\title{
SIMULATION OF IRREGULAR WAVE PRESSURE ON PERFORATED BREAKWATERS
}

\author{
Xuefeng CHEN ${ }^{1}$ Yucheng $\mathrm{LI}^{2}$ and Liu YONG ${ }^{3}$
}

\begin{abstract}
In this paper, the wave pressures on the perforated caissons breakwaters are investigated. The front wall of the perforated caissons is usually perforated above a certain water level considering the stability of the structure, and the chamber of the perforated caisson is filled with rock. Based on the RANS and k- $\varepsilon$ equations, the numerical method to simulate the interaction of the irregular wave with the perforated breakwaters is researched. Moreover, the wave pressures distribution on the front perforated wall and the back wall are discussed through the numerical calculations, respectively. Then, the simplified formulas to compute the wave pressures on the different position of perforated caisson are obtained from experimental data by using the least-squares method.
\end{abstract}

Keywords: wave pressure; perforated caissons; irregular wave; numerical calculation

\section{INTRODUCTION}

The perforated caisson is effective in absorbing wave energy and reducing the wave pressure on the protective structure. Therefore, the distribution of wave pressures acting on the perforated caisson is important to design the breakwaters. Fugazza and Natale (1992) and Bennett et al. (1992) have theoretically analyzed the reflection coefficient of a perforated caisson by use of potential flow theory. Suh et al. (2001) developed an analytical model to predict the reflection characteristics of irregular wave incident on perforated structures through a frequency-average method. Some studies on the calculation of wave pressure can also be found in the published literature. For example, Takahashi (1996) revised Goda's formula and presented an empirical model to calculate the wave pressures on perforated caissons (TAKAHASHI formula). In this widely accepted empirical model, three different situations of maximum wave pressure are considered. Tabet- Aoul and Lambert (2003) experimentally developed TAKAHASHI formula to calculate the wave pressure on this type of structure, and the formula considered the effect of the porosity and phase difference on the total horizontal forces (Tabet formula).

The above researches were focused on the experiment test. In addition, Isaacson et al. (2000) and Teng et al. (2004) developed the analytical solutions based on the matched eigen-function method to study the horizontal forces on different perforated caissons. Recently, Liu et al. (2006) have investigated the total horizontal and vertical regular wave forces on partially perforated caisson breakwaters. More recently, Liu et al. (2008) presented analytical results on the wave forces of irregular waves on partially perforated breakwater. The above references discuss the irregular wave pressures on the perforated breakwaters through the experimental investigation and analytical method. However, a direct numerical method including the nonlinearity and viscosity was proposed to simulate the wave action the structure. Chen et al. (2007) have numerically calculated the horizontal wave force of regular wave acting on perforated breakwaters based on the RANS and k- $\varepsilon$ equations.

This paper develops a direct numerical model which combines the RANS and $k-\varepsilon$ equations to accurately simulate the nonlinear interaction between the irregular waves and porous breakwaters. The volume of fluid (VOF) method is applied to trace the free surface, and the internal source generation of wave is applied to simulate the irregular wave propagation. And an experiment is carried on to verify the numerical method and results. Moreover, the simplified formulas to compute the wave pressures on the different position of perforated caisson are obtained from experimental data by using the leastsquares method.

\section{GOVERNING EQUATION}

\section{Governing equations}

Cartesian coordinates $(\mathrm{x}, \mathrm{y})$ are employed, with the $\mathrm{y}$-axis directed vertically upwards from the origin in the bed, and the $\mathrm{x}$-axis pointing horizontally to the right. Assuming the flow to be non-viscous

\footnotetext{
${ }^{1}$ R\&D center of Civil Engineering Technology, Dalian University, Dalian 116622, Liaoning, China

${ }^{2}$ State Key Laboratory of Coastal and Offshore Engineering, Dalian University of Technology, Dalian 116023, Liaoning, China

${ }^{3}$ College of Engineering, Ocean University of China, Qingdao 266100, China
} 
and incompressible, the governing equations for the flow include the continuity equation and the Reynolds averaged Navier-Stokes equations:

$$
\begin{aligned}
& \frac{\partial u_{\mathrm{i}}}{\partial x_{i}}=0 \\
& \frac{\partial u_{i}}{\partial t}+u_{j} \frac{\partial u_{i}}{\partial x_{j}}=-g_{i}-\frac{1}{\rho} \frac{\partial p}{\partial x_{i}}+\frac{\partial}{\partial x_{j}}\left[v\left(\frac{\partial u_{i}}{\partial x_{j}}+v_{t}\left(\frac{\partial u_{i}}{\partial x_{j}}+\frac{\partial u_{j}}{\partial x_{i}}\right)-\frac{2}{3} \delta_{i j} k\right]\right.
\end{aligned}
$$

Here $u_{\mathrm{i}}(\mathrm{i}=1,2)$ is the velocity component in the $x_{\mathrm{i}}$ direction, $p$ is the pressure, $\rho$ is the density of the fluid, $v$ is the coefficient of kinematic viscosity and $g$ is the gravitational acceleration, and $\delta_{\mathrm{ij}}=1$ for $\mathrm{i}=\mathrm{j}$ and $\delta_{\mathrm{ij}}=0$ for $\mathrm{i} \neq \mathrm{j}$.

The turbulent $\mathrm{k}-\varepsilon$ model was used to solve the moment equation.

$$
\begin{aligned}
& \frac{\partial k}{\partial t}+u_{j} \frac{\partial k}{\partial x_{j}}=\frac{\partial}{\partial x_{j}}\left[\left(v+\frac{v_{t}}{\sigma_{k}}\right) \frac{\partial k}{\partial x_{j}}\right]+v_{t}\left(\frac{\partial u_{i}}{\partial x_{j}}+\frac{\partial u_{j}}{\partial x_{i}}\right) \frac{\partial u_{i}}{\partial x_{j}}-\varepsilon \\
& \frac{\partial \varepsilon}{\partial t}+u_{j} \frac{\partial \varepsilon}{\partial x_{j}}=\frac{\partial}{\partial x_{j}}\left[\left(v+\frac{v_{t}}{\sigma_{k}}\right) \frac{\partial \varepsilon}{\partial x_{j}}\right]+C_{\varepsilon 1} \frac{\varepsilon}{k} P_{k}-C_{\varepsilon 2} \frac{\varepsilon^{2}}{k}
\end{aligned}
$$

Where $k$ is the turbulent kinetic energy, $\varepsilon$ is the turbulent dissipation rate and $v_{t}=C_{\mu} k^{2} / \varepsilon$ is the coefficient of turbulent viscosity. The coefficients in Eqs. (3) and (4) have been measured as $\mathrm{C}_{\mu}=0.09$, $\sigma_{\mathrm{k}}=1.00, \sigma_{\varepsilon}=1.30, \mathrm{C}_{\varepsilon 1}=1.44$ and $\mathrm{C}_{\varepsilon 2}=1.92$ (Rodi, 1980).

\section{Boundary condition}

The internal source function (Lin and Liu, 1999) is adopted to generate the incident irregular wave. On the wave-maker boundary, Eq. (1) is modified as follows:

$$
\frac{\partial u_{\mathrm{i}}}{\partial x_{i}}=s\left(x_{i}, t\right) \quad \text { in } \Omega
$$

Where $s\left(x_{i}, t\right)$ is nonzero mass source function within the region $\Omega$. The source region $\Omega$ is the width of about $5 \%$ of the significant wave length of the incident wave. There is a sponger layer lying at the end of the source region. The target wave is simulated as JONSWAP spectrum.

In order to trace the free surface, the volume of fluid (VOF) method was used. The $F$ function is defined as follows: the average value of $F$ in a cell equals the fractional volume of the cell occupied by fluid. In particular, a unity value of $F$ corresponds to a cell full of fluid, whereas a zero value indicates that the cell contains no fluid. Cells with $F$ values between zero and one are partially filled with fluid and either are intersected by a free surface or contain voids (bubbles) smaller than the dimensions of the cell mesh. The time dependence of $F$ is governed by:

$$
\frac{\partial F}{\partial t}+\frac{\partial}{\partial x_{i}}\left(u_{i} F\right)=0
$$

Because $F$ is a step function, its derivatives must be taken into consideration by a form of donoracceptor differencing. And the upwind difference scheme was applied to solve the above numerical equations (Chen 2007). The iterative precision of equation is less than $10^{-5}$.

\section{EXPERIMENTAL VERIFICATION}

To verify the numerical results, an experiment was carried out in a wave flume (Fig.1) at the State Key Laboratory of Coastal and Offshore Engineering, Dalian University of Technology. The flume was $56 \mathrm{~m}$ in length, $0.7 \mathrm{~m}$ in width and $1.0 \mathrm{~m}$ in height. The water depth $\mathrm{d}$ before the structure kept constant $0.40 \mathrm{~m}$. And the water depth $\mathrm{d}_{1}$ in the chamber was $0.20 \mathrm{~m}$. Table 1 showed the test condition. The target spectrum is JONSWAP spectrum. Table 2 presents the combination of the wave significant period and the wave significant height. 


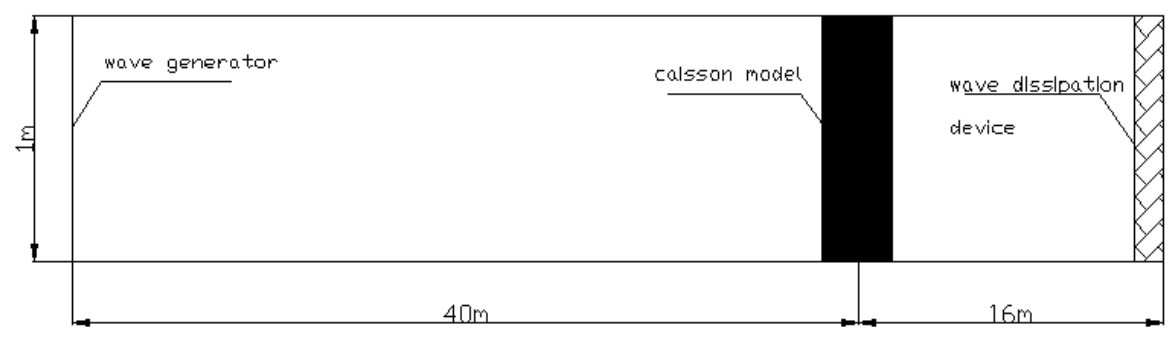

Fig. 1 Planform of the experimental setup

\begin{tabular}{|c|c|c|c|}
\hline Physical parameter & Test values & Physical parameter & Test values \\
\hline Significant period Ts (s) & $1.00,1.15,1.40$ & Porosity $\mu$ & $0.20,0.40$ \\
\hline Significant height $\mathrm{H} 1 / 3$ & $0.053,0.067,0.08$ & Wave steepness $\left(H_{1 / 3} / L_{1 / 3}\right)^{\text {a }}$ & $0.02-0.06$ \\
\hline Width of chamber bc & $0.10,0.20,0.30$ & $\begin{array}{l}\text { Relative width of chamber } \\
\left(b_{c} / L_{1 / 3}\right)\end{array}$ & $0.064-0.21$ \\
\hline Water depth in front of chamber $d$ & 0.40 & Relative water depth $\left(d / L_{1 / 3}\right)$ & $0.17-0.28$ \\
\hline
\end{tabular}

${ }^{\mathrm{a}} L_{1 / 3}$ represents the significant wavelength.

\begin{tabular}{|c|c|c|c|c|c|c|c|c|c|}
\hline Wave Significant period T (s) & 0.99 & 1.02 & 1.01 & 1.14 & 1.15 & 1.16 & 1.38 & 1.39 & 1.41 \\
\hline Significant wave height $(\mathrm{cm})$ & 5.28 & 6.82 & 8.10 & 5.34 & 6.86 & 8.12 & 5.32 & 6.83 & 8.15 \\
\hline
\end{tabular}

Model made of plexiglass is $0.45 \mathrm{~m}$ long, $0.68 \mathrm{~m}$ wide and $0.70 \mathrm{~m}$ high, respectively. The perforated caisson has one chamber. The front wall is perforated with four rectangular holes and the back wall is solid. The porosities $(\mu)$ of the front wall are $20 \%$ and $40 \%$, respectively. Here, the porosity is defined as the ratio of the holes' area to the front plate's total area. The length of the hole is $0.142 \mathrm{~m}$ and its width is $0.038 \mathrm{~m}$ when $\mu$ is $20 \%$, when $\mu$ is $40 \%$ the width of the hole is $0.076 \mathrm{~m}$ and the length of hole is the same as $20 \%$ porosity. The impermeable portion in the chamber is filled with the different size of rock.

Measuring the pressure distribution on the different position on the front perforated wall of the structure (Fig. 2), 43 sets of the pressure gauges whose natural vibration frequency are about $500 \mathrm{~Hz}$ were fixed on the different positions (front wall, back wall and the bottom plates). The arrangement of wave pressure gauges on the back wall is same as the outer side of the front wall. Table 3 displays the distance from the pressure gauges to the bed.

Table 3. Distances from the pressure gauges to the bed.
\begin{tabular}{|l|l|l|l|l|l|l|}
\hline Pressure gauges & No. 1 & No. 2 & No. 3 & No. 4 & No. 5 & No. 6 \\
\hline Distance (cm) & 1.0 & 10.0 & 20.0 & 32.6 & 43.9 & 54.8 \\
\hline
\end{tabular}

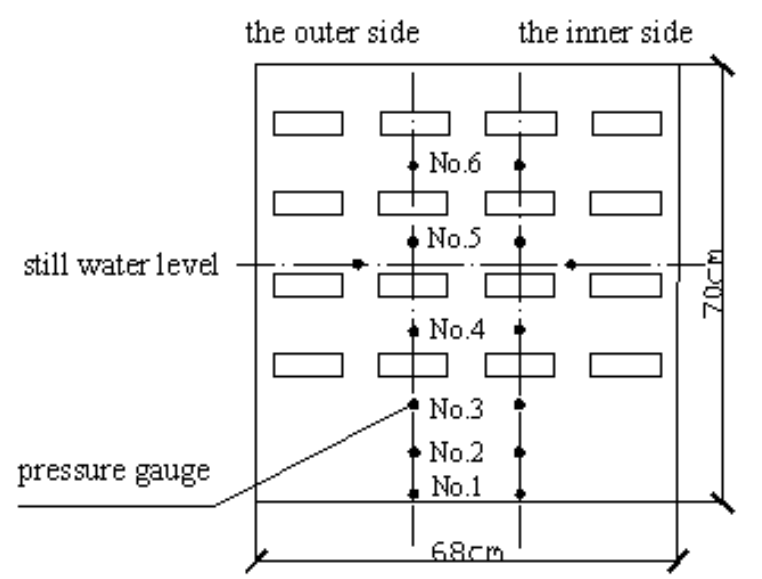

Fig. 2. Positions of pressure gauges on the front perforated wall 
The wave pressures distribute on the outer and inner of front wall and on the back solid wall. Therefore, the wave pressure difference between the outer and inner of front wall is regarded as the index to pressure on the front wall. Fig. 3 illustrates the comparison between the numerical results and the measured data for the wave pressure difference between the inner and outer side of the front wall of perforated caisson near the still water level. It is seen that the numerical results are well verified by the experimental data. The wave pressure differences on the toe of perforated caisson are compared in Fig. 4. And Fig. 5 shows the comparison the wave pressure on the back wall near the still water level. The same results are seen from Figs. 4-5 as Fig. 3 that the numerical results are agreeable well with the experimental data. Accordingly, a conclusion can be drawn that the numerical method proposed here may be used to simulate the action of the irregular wave on a perforated caisson.

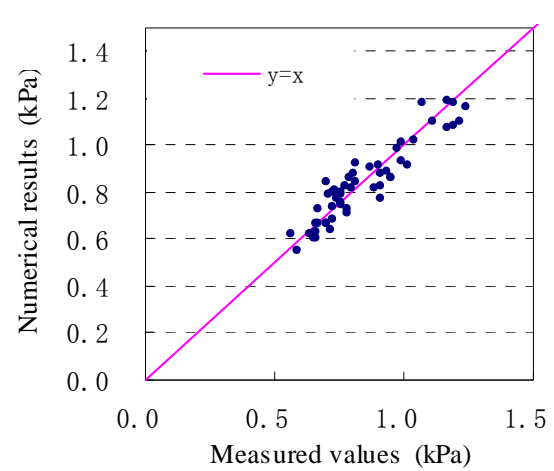

Fig. 3

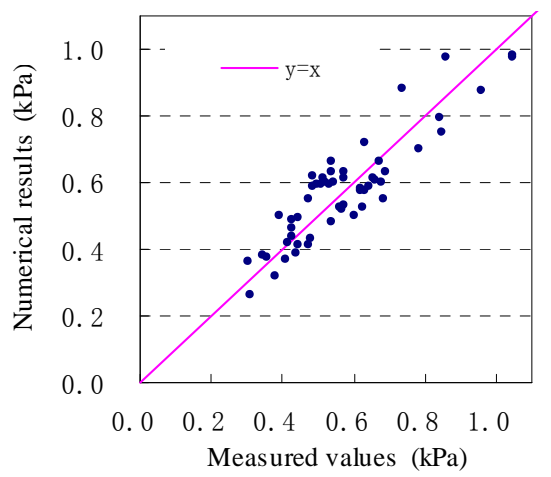

Fig. 4

Fig. 3. Numerical results vs. test data the comparison: the wave pressure difference near the still water level of front wall of perforated caisson

Fig. 4. Numerical results vs. test data the comparison: the wave pressure on the toe perforated caissons

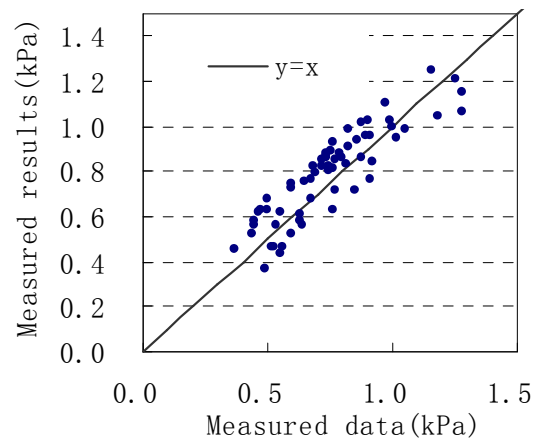

Fig. 5. Numerical results vs. test data the comparison: the wave pressure on the still water level of back wall

\section{DISCUSSION}

According to Liu (2008) and Chen's (2007) research, the relationship between wave force and its main influencing parameters can be expressed as: $P=f\left(d / L_{s}, b_{c} / L_{s}, H_{s} / L_{s}, \mu\right)$. Based on the numerical results, the main parameters affecting the wave pressure distribution are discussed by the correlative analysis method. Fig. 6 shows the effect of relative water depth $\left(d / L_{s}\right)$ on the wave pressure difference on the still water level of front perforated wall $\left(\Delta p_{s} / \rho g H_{s}\right)$. In this figure, the relative chamber width keeps constant. It is illustrated that the relationship between $d / L_{\mathrm{s}}$ and $\Delta p_{s} / \rho g H_{s}$ is linear degression. The relation between the relative chamber width and $\Delta p_{s} / \rho g H_{s}$ is illustrated in Fig.7. it is clearly seen that the effect of $b_{c} / L_{\mathrm{s}}$ on $\Delta p_{s} / \rho g H_{s}$ is linear degression. The effect of other factors on the wave pressure is also discussed, then a conclusion can be drawn that the relationship between $b_{c} / L_{s}, H_{s} / L_{s}$ and $\Delta p_{s} / \rho g H_{s}$ is regarded as linear. Porosity is assumed as linear influence on $\Delta p_{s} / \rho g H_{s}$. 


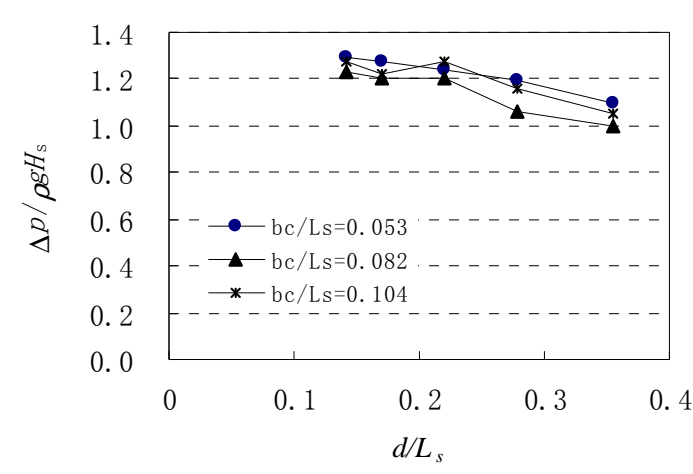

(a) $\quad \mu=20 \%$

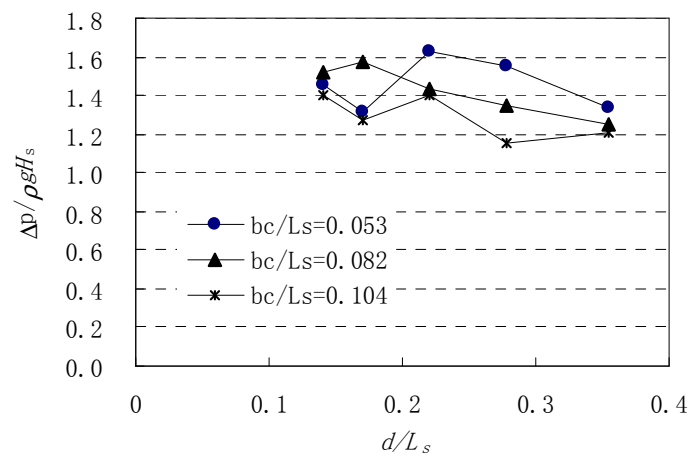

(b) $\mu=40 \%$

Fig.6 the correlative relationship between the relative water depth and the pressure difference on the still water level of front wall of perforated caissons

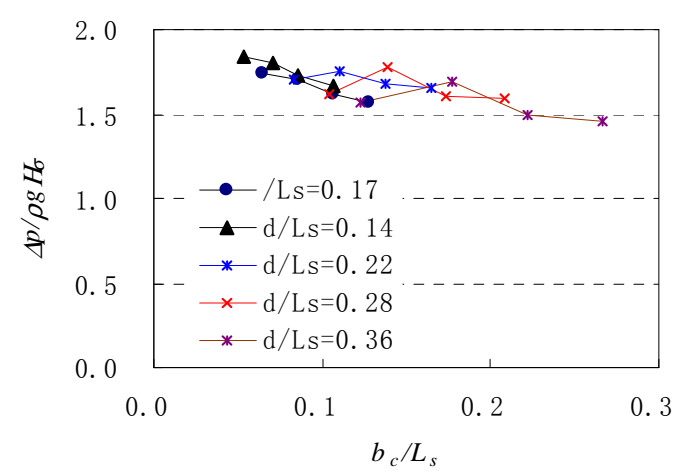

(a) $\quad \mu=20 \%$

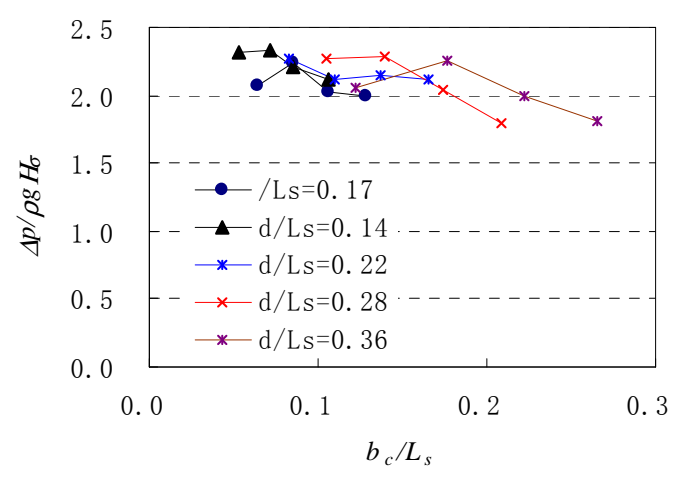

(b) $\mu=40 \%$

Fig.7 the correlative relationship between the relative water depth and the pressure difference on the still water level of front wall of perforated caissons

According to the analysis of the numerical results, the simplified formulas to compute the wave pressures on the different position of perforated caisson are obtained from experimental data by using the least-squares method. Eq.7 expresses the relationship between the wave pressure difference $\left(\Delta p_{\mathrm{s}}\right)$ between the outside and inner of the front wall of perforated caisson near the still water level and its main affecting parameters including the width of chamber, the water depth, wave steepness and porosity. The correlative coefficient of Eq.7 is 0.85 . The results between the measured data and simplified results from Eq.7 are compared in Fig.8. The horizontal axis is the simplified results from Eq. 7, and the vertical axis is the measured data, the diagonal expresses the horizontal values equal to the vertical values. It is seen that the most points are near the diagonal, that is to say, Eq. 7 can express the experimental characteristic.

The simplified expressions to compute the wave pressure on the toe of perforated caissons $\left(p_{d}\right)$ is proposed as Eq.8. The correlative coefficient of Eq.8 is 0.87 . Fig. 9 plots the comparison between the measured data and simplified results obtained from Eq. 8. This figure reveals that the measured data accord with the simplified results. The expressions of these simplified formulas are simple and useful for actual engineering design.

$$
\begin{aligned}
& \frac{\Delta p_{s}}{\rho g H_{1 / 3}}=6.794-4.824\left(\frac{b_{c}}{L_{1 / 3}}\right)-2.256\left(\frac{d}{L_{1 / 3}}\right)-8.158\left(\frac{H_{1 / 3}}{L_{1 / 3}}\right)+7.362 \mu \\
& \frac{p_{d}}{\rho g H_{1 / 3}}=4.949-6.75\left(\frac{b_{c}}{L_{1 / 3}}\right)-4.292\left(\frac{d}{L_{1 / 3}}\right)-3.204\left(\frac{H_{1 / 3}}{L_{1 / 3}}\right)+7.184 \mu
\end{aligned}
$$




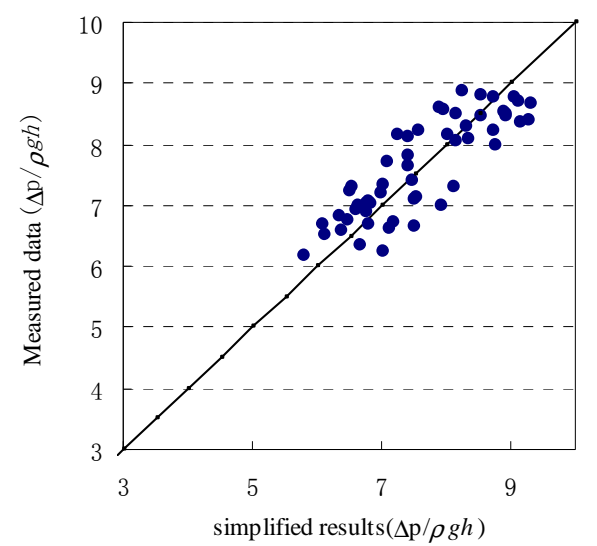

Fig.8 Measured data vs. simplified results from Eq.7

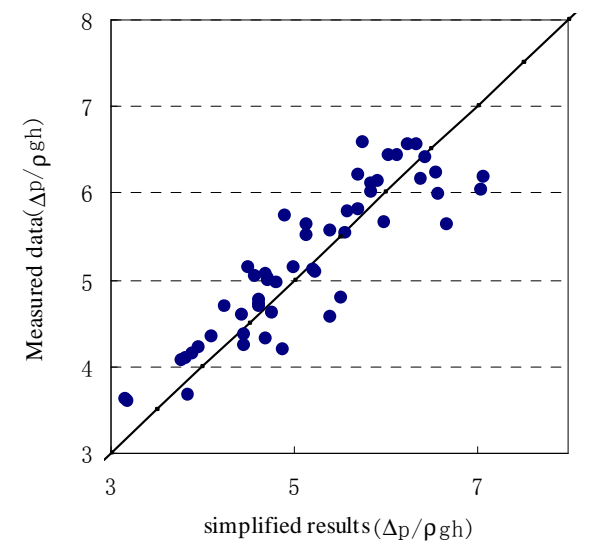

Fig.9 Measured data vs. simplified results from Eq.8

\section{CONCLUSION}

Based on the RANS and k- $\varepsilon$ equations, a numerical method to simulate the interaction of the irregular wave with the perforated breakwaters is established. The internal source generation of wave is applied to simulate the irregular wave propagation. Moreover, an experiment is carried out to verify the numerical method. Then, the correlative analysis is adopted to investigate the main parameters influencing the irregular wave pressures based on the numerical results. It is known that the main parameters include the relative chamber width, the relative water depth, wave steepness and porosity. At last, the simplified formulas are obtained from the measured data based on the Least-square Method. However, the simplified formulas are used in the range of experiment.

\section{ACKNOWLEDGMENTS}

This work is supported by Fund of the National Natural Science Foundation of China (50609001, 50909086).

\section{REFERENCES}

Bennett, G.S., McIver, P. and Smallerman, J.V. 1992. A mathematical model of a slotted wavescreen breakwater, Coastal Eng. 18, 231-249.

Chen, X.F., Li, Y.C. and Teng, B. 2007. Numerical and simplified methods for the calculation of the total horizontal wave force on a perforated caisson with a top cover. Coastal Engineering, 54, 6775.

Fugazza, M., Natale, L. 1992. Hydraulic design of perforated breakwaters, Journal of Waterway, Port, Coastal and Ocean Eng., ASCE, 118(1), 1-14.

Isaacson, M., Baldwin, J., Allyn, N. and Cowdell, S. 2000. Wave interactions with perforated breakwater. Journal of Waterway, Port, Coastal, and Ocean Engineering, ASCE 126 (5), 229-235.

Liu Y., Li, Y.C., Teng, B., Jiang J.J. and Ma B.L. 2008. Total horizontal and vertical forces of irregular waves on partially perforated caisson breakwaters, Coastal Engineering, 55, 537-552.

Liu, Y., Li, Y.C., Teng, B. and Jiang, J.J. 2006. Experimental and theoretical investigation of wave forces on a partially-perforated caisson breakwater with a rock-filled core. China Ocean Engineering, 20 (2), 179-198.

Rodi, W. 1980. Turbulence models and their application in hydraulics - a state of the art review. International Association for Hydraulic Research, Delft, Netherlands.

Suh, K.D., Choi, J.C., Kim, B..H, Park, W.S. and Lee, K.S. 2001. Reflection of irregular waves from perforated-wall caisson breakwaters. Coastal Engineering, 44, 141-151.

Tabet-Aoul, E.H. and Ambert, E. 2003. Tentative new formula for maximum horizontal wave forces acting on perforated caisson. J. Waterway, Port, Coastal Ocean Eng, 129(1), 34-40.

Takahashi, S. 1996. Design of vertical breakwaters, Port and Harbor Research Institute, Ministry of Transport, Japan, Reference Document N34.

Teng, B., Zhang, X.T. and Ning, D.Z. 2004. Interaction of oblique waves with infinite number of perforated caissons. Ocean Engineering, 31, 615-632. 